\title{
Percutaneous Pinning of Fractures of the Surgical Neck of the Humerus in Children and Adolescents
}

\author{
Khaled A. Maziad ${ }^{1, *}$ MSc; Yusuf H. Gad ${ }^{1}$ MD ; Amro A. Fouaad ${ }^{1}$ MD
}

\author{
*Corresponding Author: \\ Khaled A. Maziad \\ drkhaledmaziad@gmail.com
}

Received for publication November 26, 2020; Accepted january 6, 2021; Published online january 6, 2021.

Copyright 2020 The Authors published by Al-Azhar University, Faculty of Medicine, Cairo, Egypt. All rights reserved. This an openaccess article distributed under the legal terms, where it is permissible to download and share the work provided it is properly cited. The work cannot be changed in anyway or used commercially.

doi: 10.21608/aimj.2021.45271.1333

${ }^{1}$ Orthopedic Surgery Department, Faculty of Medicine, Al-Azhar University, Cairo, Egypt.

\begin{abstract}
Background: Proximal humerus fractures occur in children of all ages, from newborn babies to teenagers, accounting for about $2 \%$ of all childhood fractures, with the highest occurrence among the ages of 11 and 15.

Aim of work: To review and evaluate the outcomes of operative procedure of surgical neck-humerus fractures in children and adolescents using closed reductions and percutaneous pinning.

Patient and Methods: 20 sufferers enrolled with Proximal Humeral Fracture Displaced in the Orthopedic Surgery Department of the AL Hussein Hospital of the Al-Azhar University Medical Faculty from January 2018 to September 2019 were involved in the current research. Closed reductions and percutaneous Kirscher wires (K-wires) have been used to treat the patients surgically. Ten patients treated with threaded Kwires and other patients with unthreaded K-wires. All patients were examined in the outpatient department using postoperative $\mathrm{x}$-rays to assess healing time and the postoperative range of motion.

Results: Regarding complications, group A, 10 (100.0\%) of the patients had no complications. Group B $8(80.0 \%)$ of the patients had no complications, $2(20.0 \%)$ of the patients showed a pin-site infection and no malunion was found. Regarding the healing time, $4(40.0 \%)$ of the patients healed in the 1 st month and $6(60.0)$ of the patients in the 2 nd month in both groups.

Conclusion: Proximal humeral fractures may be managed using percutaneous pinning, which provides effective reduction and adequate temporary stabilization. This treatment modality was not correlated with any significant complications, like deep infection, avascular necrosis, or neurovascular deficiency.

Keywords: pinning; fractures; surgical neck; humerus; children; $K$ wires.
\end{abstract}

Disclosure: The authors have no financial interest to declare in relation to the content of this article. The Article Processing Charge was paid for by the authors.

Authorship: All authors have a substantial contribution to the article.

\section{INTRODUCTION}

Around $2 \%$ of all pediatric fractures are due to proximal humeral fractures (PHFs). These fractures become most frequent in teenagers aged 11-15 years and are more common in men with a 3-to-1 ratio of men to women. ${ }^{1}$

The life-span occurrence distribution of PHFs indicates an early, modest peak of among 10 and 14 years, accompanied by low values in younger people and a rise to a maximum of 70 years after 45 years, in children and adolescents, PHFs only contribute $0.5 \%$ to $3.5 \%$ of all fractures. ${ }^{2}$

The proximal humeral physis responsible for $80 \%$ of the longitudinal development of the upper arm and offers huge potential for remaining axial abnormalities to be corrected, severely displaced fractures can require surgical intervention in older children with lower residual growth to preserve anatomical alignment and optimize shoulder movement. Although most pediatric proximal humeral fractures may be managed conservatively with adequate outcomes, several surgical procedures, which include Kirschner (K) wires, screws, and elastic nails, and have become accessible for the treatment of, displaced proximal humeral fractures $3,4,5$

Closed reduction and percutaneous fixation became first defined for the management of pediatric proximal humerus fractures. With the patient under general anesthesia, the fracture decreased and the fragment of the humeral head was temporarily connected to the shaft with pins placed percutaneously. ${ }^{6}$

Boys in most pediatric and adolescent age categories are three to four times more likely than girls to develop a proximal humerus fracture. ${ }^{7}$

In children and young adults, two classic traumatic mechanisms are believed to be responsible for this injury, the first is a direct trauma caused by a fall directly on the shoulder or a sharp impact or a hit. An indirect fall on an extended hand is the second 
mechanism, with the arm abducted and rotated from the outside. ${ }^{8}$

The older child is involved in both overt and indirect trauma to the proximal humerus. The leading trigger of fractures of the proximal humerus in children is injuries from sports, vehicles, or road crashes and falls. Six injury mechanisms were reported by Williams: forced extension, forced flexion, lateral or medial rotation flexion and forced lateral or medial rotation extension. ${ }^{9}$

Repeated injuries may also harm the proximal humeral physics. There have been records of slippage of the proximal humeral growth plate in gymnasts. ${ }^{10}$

Pathological fractures arising from benign lesions have been reported, especially popular benign lesions that cause pathological fractures by the proximal humerus, which include aneurysmal and unicameral bone cysts.

The risk of proximal humeral fractures is possibly increased by factors which raise the risk or intensity of the fall, recent declines in health, insulin-dependent diabetes mellitus, infrequent walking, epilepsy and neuromuscular impairment are independent risk variables correlated with a raised rate of proximal humeral fractures in children. ${ }^{12}$

ESIN retrograde. In accordance with the principles of minimally invasive internal fixation which becomes gentle on the neighboring soft tissues, this procedure requires retrograde nailing. 13

Several studies describing surgeons' experiences with ESIN have been published over the past decade. ${ }^{14}$

To treat these fractures, different approaches of open reduction and internal fixation may be utilized. There are possible disadvantages for open reduction and internal fixation, at the time of reduction and / or hardware usage; extensive soft tissue stripping can harm the humeral head vasculature, growing the risk of avascular humeral head necrosis. ${ }^{15}$

\section{PATIENT AND MATERIALS}

The prospective comparative research included 20 sufferers with displaced proximal humeral fractures in children and adolescent admitted to the department of orthopedic surgery (AL-Hussein Hospital), Al-Azhar University Faculty of Medicine during the period from January 2018 to September 2019.

Ten (10) patients have been managed with closed reduction and percutaneous pinning by $\mathrm{K}$-wires (Threaded ended), and other patients by Kirscher wires.

All patients have been checked in the outpatient department by a postoperative $\mathrm{x}$-ray to assess the healing, the healing time, the post-surgery range of movement regard to the type of fracture, the angulation and the displacement of the fracture.

The study included patients aged 5 to 17 years, Neer Type III, Type IV, full physical examination of the fractured limb, and no neurovascular injury.

Pre-operative planning:
Complete history taking about the mechanism of the fracture. Preoperative X-ray film to identify the fracture site, the angulation, the proximal and distal fracture segments. Complete neurovascular inspection of the affected limb. It is necessary to take preoperative intravenous antibiotics.

Intra-operative:

Patient Position: In order to make sure the whole shoulder girdle is exposed for fluoroscopic imaging, the patient is put on a standard operating table with a long beanbag shaped medial to the shoulder blade, this position of the patient enables antero-posterior and axillary lateral images of the affected shoulder.

\section{Reduction:}

The first step generally includes abduction and external rotation of the arm to reduce the fracture. Use the image intensification to manipulate the distal fragment through minor external rotation, flexion of 90 degrees and abduction of 70 degrees. Satisfactorily puts together the fragments. Get the assistant assist the proximal fragment in achieving and sustaining the reduction .

Fixation technique:

Entry site: The entrance of the k-wire should be at the side of the tip of the acromion, away from the axillary nerve, which is located in the deltoid, $5 \mathrm{~cm}$ (less in an adult in a child). For dissecting the tissue down to the bone, percutaneous small stab incisions. Drill two smooth Steinmann pins or threaded wires via the lateral shaft in the proximal direction into the humeral head, depending on the stability of the fractures, to preserve the reduction. Cut off the pins under the skin after 4-6 weeks to remove them .

Post-operative:

Immobilization in the arm in a sling for follow up and Post-operative plain X-ray for follow up of reduction of fracture.

Male patient 11 yrs. old presented by displaced surgical neck fractures after fall onto an outstretched hand

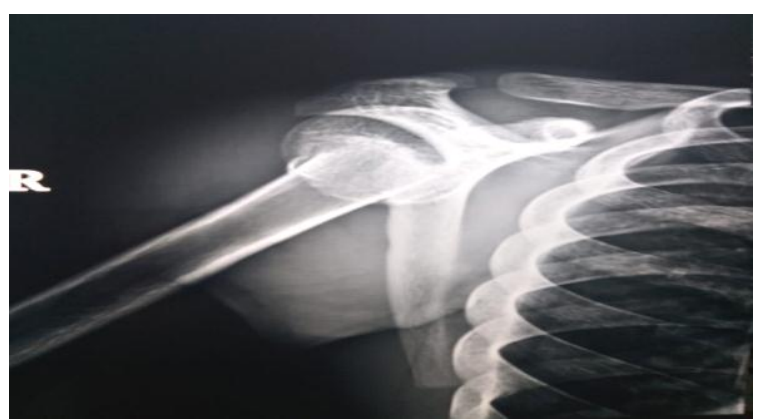

Fig. 1: Pre-intervention X-ray films. 


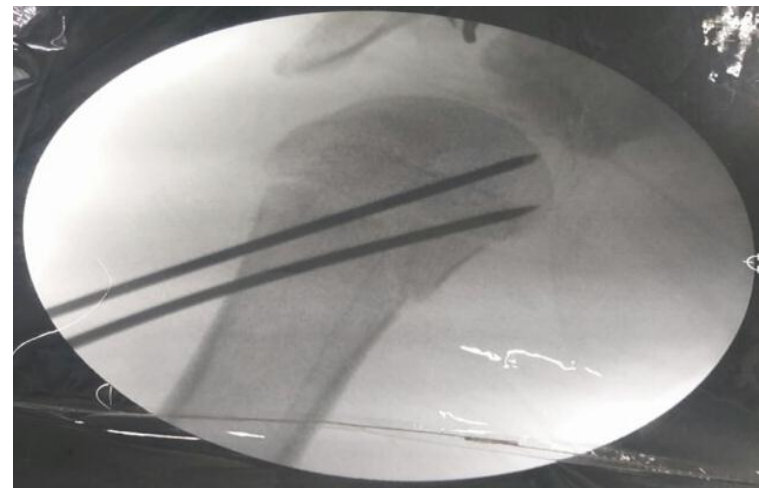

Fig. 2: Intraoperative X-ray films by C-Arm.

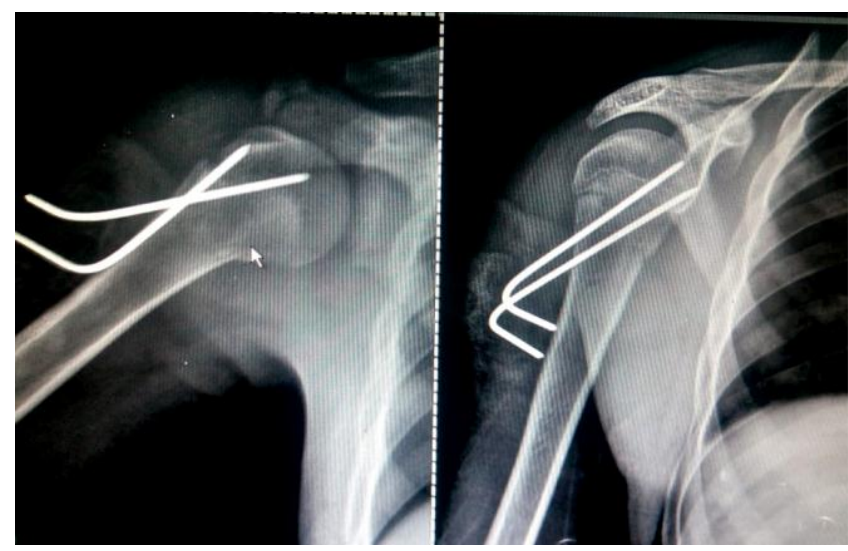

Fig. 3: Post-operative X-ray film

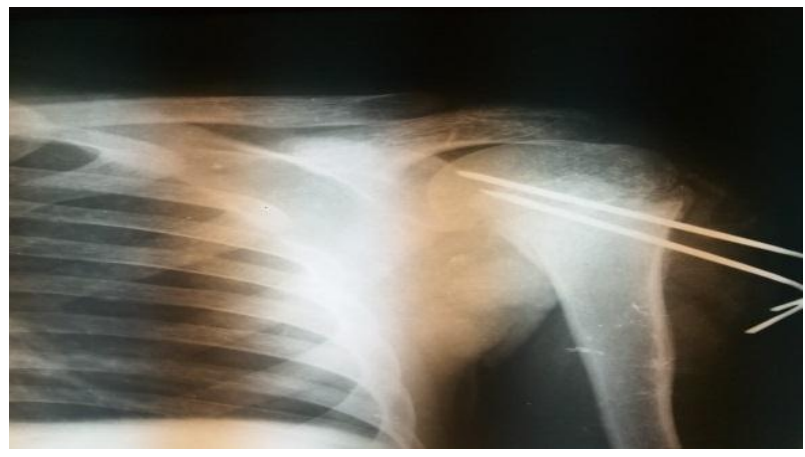

Fig. 4: After 4 weeks

Male patient 14yrs old presented with fracture of left proximal humerus after direct trauma to the shoulder

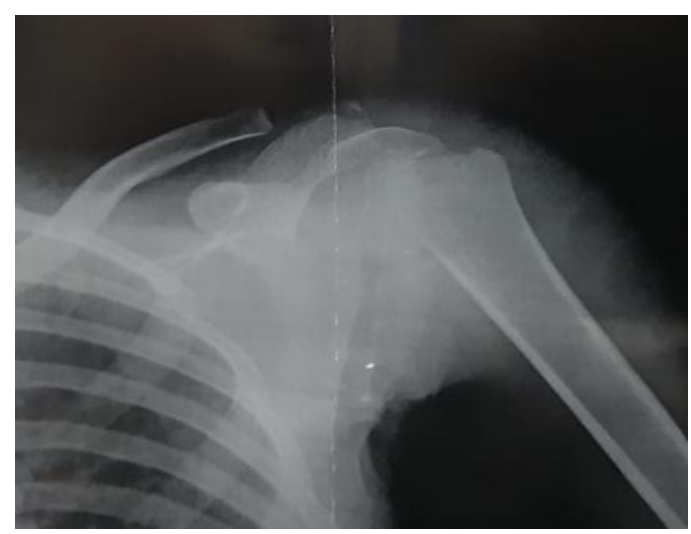

Fig. 5: Pre-operative x-ray

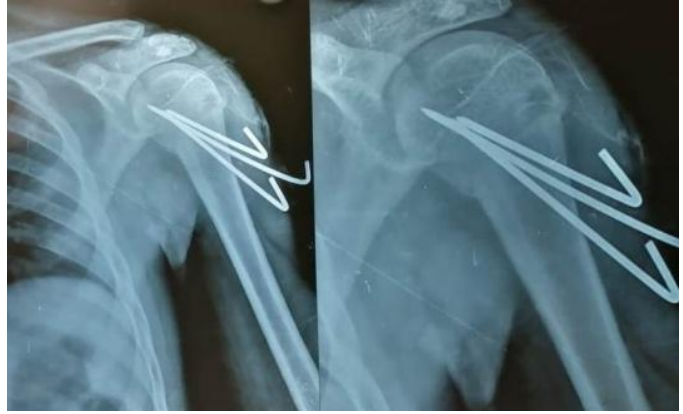

Fig. 6: Post-operative x-ray

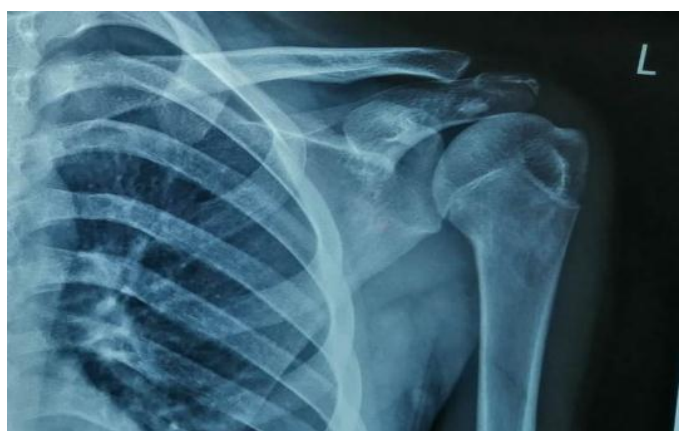

Fig 7: Plain x-ray at the end of follow up

\section{RESULTS}

Patients of the study were classified into two groups group A included ten managed with closed reduction and percutaneous pinning by Threaded ended -wires; while group B also included ten patients treated by Kirschenr-wires.

Demographic data

\begin{tabular}{|c|c|c|c|c|c|c|}
\hline \multirow{2}{*}{ Sex } & \multicolumn{2}{|c|}{$\begin{array}{l}\text { Group A } \\
(\mathbf{n}=10)\end{array}$} & $\begin{array}{c}\text { Group B } \\
(\mathbf{n}=10)\end{array}$ & \multirow{2}{*|}{$\chi^{2}$} & $\mathbf{p}$ \\
\cline { 2 - 6 } & No. & $\%$ & No. & $\%$ & & \\
\hline Male & 7 & 70.0 & 8 & 80.0 & 0.267 & 1.000 \\
Female & 3 & 30.0 & 2 & 20.0 & & \\
\hline
\end{tabular}

Table 1: Comparison of the two sex-based groups

\begin{tabular}{|c|c|c|c|c||}
\hline Age (years) & $\begin{array}{c}\text { Group A } \\
\text { (threaded) } \\
(\mathbf{n}=\mathbf{1 0})\end{array}$ & $\begin{array}{c}\text { Group B } \\
(\mathbf{s m o o t h}) \\
(\mathbf{n}=\mathbf{1 0})\end{array}$ & $\mathbf{t}$ & $\mathbf{p}$ \\
\hline $\begin{array}{c}\text { Min. } \\
\text { Max. }\end{array}$ & $10.0-14.0$ & $7.0-10.0$ & & \\
$\begin{array}{c}\text { Mean } \pm \\
\text { SD. }\end{array}$ & $1.33 \pm 12.0$ & $1.08 \pm 8.50$ & $6.450^{*}<0.001^{*}$ & \\
$\begin{array}{c}\text { Median } \\
\text { (IQR) }\end{array}$ & $\begin{array}{c}12.0(11.0- \\
13.0)\end{array}$ & $\begin{array}{c}8.50(8.0- \\
9.0)\end{array}$ & & \\
\hline
\end{tabular}

Table 2: Comparison of the two age groups studied 
Table $(1 \& 2)$ summarizes comparison of the two groups studied as per demographic data: Group A had 7 males and 3 females, while Group B had 8 males and 2 females. In the two groups, there was statistically no substantial variation in gender distributions. Ten patients ranged in age between $10.0-14.0$ years with an average age of $12.0 \pm 1.33$ years for Group $\mathrm{A}$ and ten patients ranged in age between $7.0-10.0$ years with a mean age $8.50 \pm$ 1.08 years for Group B. Statistically, there was a substantial variation among the two groups concerning the mean age. Group A was higher in mean age than Group B .

\begin{tabular}{||c|c|c|c|c||}
\hline $\begin{array}{c}\text { Time of healing } \\
\text { (weeks) }\end{array}$ & $\begin{array}{c}\text { Group A } \\
(\mathbf{n}=\mathbf{1 0})\end{array}$ & $\begin{array}{c}\text { Group B } \\
(\mathbf{n}=\mathbf{1 0})\end{array}$ & $\mathbf{t}$ & $\mathbf{p}$ \\
\hline Min. - Max. & $3.0-8.0$ & $3.0-7.0$ & & \\
& & & & \\
Mean \pm SD. & \pm 5.30 & $1.49 \pm 5.0$ & 0.394 & 0.698 \\
& 1.89 & & & \\
Median (IQR) & $5.0(4.0-$ & $5.0(4.0-$ & & \\
& $7.0)$ & $6.0)$ & & \\
\hline
\end{tabular}

Table 3: Comparison of the two groups studied at the time of healing (weeks)

Table (3): summarizes Comparison of the two groups studied as per time of healing (weeks): in the two groups, there was a statistically insubstantial variation in the mean healing time.

\begin{tabular}{|c|c|c|c|c|c|c|}
\hline \multirow[t]{2}{*}{ Complication } & \multicolumn{2}{|c|}{$\begin{array}{c}\text { Group } \\
\text { A } \\
(\mathbf{n}=\mathbf{1 0})\end{array}$} & \multicolumn{2}{|c|}{$\begin{array}{c}\text { Group B } \\
(n=10)\end{array}$} & \multirow[t]{2}{*}{$\chi^{2}$} & \multirow[t]{2}{*}{${ }^{\mathbf{M C}} \mathbf{p}$} \\
\hline & No. & $\%$ & No. & $\%$ & & \\
\hline Free & 10 & 100.0 & 8 & 80.0 & & \\
\hline Pin site infection & 0 & 0.0 & 2 & 20.0 & & \\
\hline Malunion & 0 & 0.0 & 0 & 0.0 & 0.556 & 0.456 \\
\hline Stiffness & 0 & 0.0 & 0 & 0.0 & & \\
\hline Joint infection & 0 & 0.0 & 0 & 0.0 & & \\
\hline
\end{tabular}

Table 4: Comparison of the two groups studied according to complication

Table (4): summarizes Comparison of the two groups studied as per complication: in Group A 10 (100.0) of patients was Complication free. in Group B 8 (80.0) of patients was Complication free, 2 (20.0), of patients showed Pin site infection and no malunion, stiffness and joint infection was found, with $\mathrm{p}=$ value 0.456 .

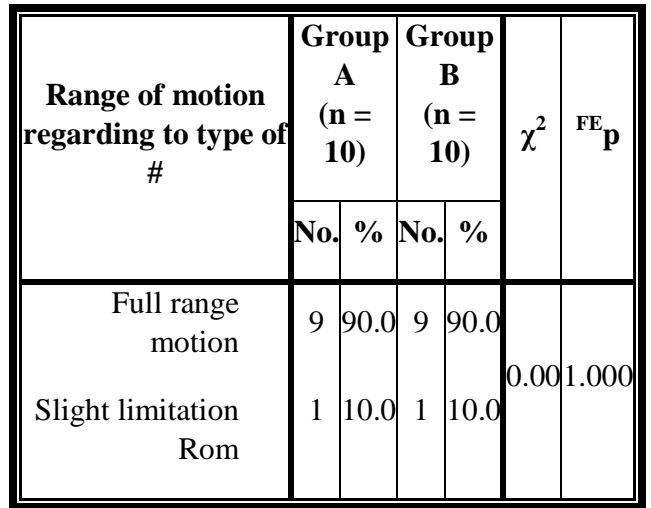

Table 5: Comparison of the two groups studied according to range of motion regarding to type of \#

Table (5): summarizes Comparison of the two groups studied as per Range of motion regarding to type of \#: in Group A 9 (90.0) of patients showed a Full range motion and 1 (10.0) of patients showed a Slight limitation Rom as well as in Group B 9 (90.0) of patients showed a Full range motion and 1 (10.0) of patients showed a Slight limitation Rom.

\section{DISCUSSION}

The life-span occurrence distribution of PHFs indicates an early, modest peak of 10 to 14 years, accompanied by low values in younger people and a rise to a maximum of 70 years after 45 years. ${ }^{16}$

Proximal humerus fractures may be solely metaphyseal or may affect physis and / or epiphysis. The minority of proximal humerus fractures are physeal fractures, with an occurrence of just 2.2 to 4.5 per 1000 per year which accounts for 4 to $7 \%$ of all physeal fractures. $85 \%$ are not displaced or minimally displaced by pediatric proximal humeral fractures. The remaining $15 \%$ are seriously displaced, which is more common in children under the age of 3 or over the age of 12 years. ${ }^{17,18}$

Recent patterns are shifting from open reduction and large internal fixation to closed reduction and percutaneous fixation (using plates and screws), as this process is less intrusive and does less harm to soft tissues. ${ }^{19,20}$

A statistically insignificant variation in the average healing time in both groups was observed in the present study. Herscovici et al. believe that there are benefits to using this technique, as long as satisfactory closed reduction can be achieved, as it not only restricts dissection but also preserves blood supply to the humeral head and percutaneous fixation leads to rapid rates of healing. ${ }^{21}$

With regard to complications, 10 (100.0) patients in group A were free of complications. In group B 8 (80.0) of the patients were free of complications, 2 (20.0) of the patients showed a pin-site infection and no malunion was found.

The most prevalent complication of percutaneous fixation is Pin Tract Infection. 22

Magovern et al., Kenner et al., and Nho et al., recorded good surgical results and comparatively few 
complications, with better percutaneous-fixation functional results. $23,24,25$

Floris in a number of 22 children treated by percutaneous pinning reported an outstanding outcome in $77 \%$ of the cases and a good outcome in $23 \%$ of the cases. $^{26}$

In a series of 16 children who were percutaneously pinning fixed, Shwendwein reported an outstanding outcome in $75 \%$ of the cases, a good outcome in $20 \%$ and a bad result in $5 \% .{ }^{27}$

Odéhouri in a series of 20 children treated by percutaneous pinning reported an outstanding outcome in $80 \%$ of the cases and a good outcome in $20 \%$ of the cases. $^{28}$

Rolauffs in a series of 43 children treated by percutaneous pinning reported an outstanding outcome in $74 \%$ of the cases, a good outcome in $22 \%$ of the cases, and a bad result in $4 \% .{ }^{29}$

Binder in a series of 72 children treated by percutaneous pinning reported an outstanding outcome in $94 \%$ of the cases and a good outcome in $6 \%$ of the cases. $^{30}$

\section{Regarding complications after fixation:}

Despite percutaneous pinning, a low infection rate was found in our series. We only found 2 superficial infections and after days of oral antibiotics, they vanished. Two potential reasons for this reduced occurrence are the compulsory weekly antiseptic therapy of inlet holes and the short period of surgery.

In the Rolauffs series, none of the 43 radiologically examined patients, postoperative angulation infections, loss of fracture reduction or implant breakage were found in the final follow-up examination. ${ }^{29}$

Floris series, the last X-ray at the end of the follow-up examination (six months) showed residual angulation in eight patients, six of whom showed restricted mobility. All were 13 years or older at the time of injury. ${ }^{26}$

In the Binder series, just a patient showed an angular deformity of over $20^{\circ}$ in the last X-ray. This can be explained by the early removal of K-wires (3 weeks) and a short follow-up period (6 months). ${ }^{30}$

In the Odéhouri series, two patients had a minor valgus deformity of no clinical significance. No physical arrest or avascular necrosis was observed. ${ }^{28}$

The use of smooth K-wires leads to loosening of the pins and a loss of reduction: $\mathrm{K}$-wires with threaded tips allow this complication to be reduced. ${ }^{31}$

\section{CONCLUSION}

Proximal humeral fractures may be managed through percutaneous pinning, which provides good fracture positioning and appropriate temporary stabilization.

This therapeutic modality has not been correlated with any significant complications, such as deep infection, avascular necrosis, non-association, or neurovascular deficiency.

\section{REFERENCES}

1. Fernandez FF, Eberhardt $\mathrm{O}$, Langendorfer $\mathrm{M}$. Treatment of severely displaced proximal humeral fractures in children with retrograde elastic stable intramedullary nailing. Injury. 2008;39: 1453-9.

2. Kim SH, Szabo RM, Marder RA. Epidemiology of humerus fractures in the UnitedStates: nationwide emergency department sample, 2008. Arthritis Care Res. 2012;64:407-14.)

3. Hutchinson PH, Bae DS, Waters PM. Intramedullary nailing versus percutaneous pin fixation of pediatric proximal humerus fractures: a comparison of complications and early radiographic results. $J$ Pediatr Orthop 2011; 31:617-22.

4. Dobbs MB, Luhmann SL, Gordon JE, Strecker WB, Schoenecker PL. Severely displaced proximal humeral epiphyseal fractures. J Pediatr Orthop 2003; 23:208-215.

5. Chee Y, Agorastides I, Garg N, Bass A, Bruce C. Treatment of severely displaced proximal humeral fractures in children with elastic stable intramedullary nailing. J Pediatr Orthop B 2006; $15: 45-50$

6. Bohler J: Les fractures recentes de l'epaule. Acta Orthop Belg 1964;30:235

7. Schwendenwein E, Hajdu S, Gaebler C, Stengg K, Vécsei V. Displaced fractures of the proximal humerus in children require open/closed reduction and internal fixation.Eur $J$ Pediatr Surg 2004;14(1):51-5.

8. Binder H, Schurz M, Aldrian S, Fialka C, Vécsei V. Physeal injuries of the proximal humerus: Long-term results in seventy two patients. Int Orthop 2011;35(10): 1497-502.

9. Williams DJ. The mechanisms producing fractureseparation of the proximal humeral epiphysis. $J$ Bone Joint Surg(Am) 2001; 63-A:102.

10. Lipscomb AB. Baseball pitching injuries in growing athletes. J Sports Med 1975; 3:25-34.

11. Ahn JI, Park JS. Pathological fractures secondary to unicameral bone cysts. Int Orthop 1994; 18:20-2

12. Halder AM, Itoi E, An K: Anatomy and biomechanics of the shoulder. Orthop Clin North Am 2000; 31: 159-76.

13. Sénès FM, Catena N. Intramedullary osteosynthesis for metaphyseal and diaphyseal humeral fractures in developmental age. J Pediatr Orthop B 2012;21:3004.

14. Khan A, Athlani L, Rousset M, Samba A, Canavese F (2014) Functional results of displaced proximal humerus fractures in children treated by elastic stable intramedullary nail. Eur J Orthop Surg Traumatol24: 165 \pm 172 . https://doi.org/10.1007/s00590-013-1177-2 PMID: 23412318]

15. Gerber C, Schneeberger A, Vinh T: The arterial vascularization of the humeral head: An anatomical study. J Bone Joint Surg (Am) 1990; 72-A:1486-94. 
16. . Kim SH, Szabo RM, Marder RA. Epidemiology of humerus fractures in the UnitedStates: nationwide emergency department sample, 2008. Arthritis Care Res2012;64:407-14.

17. Bahrs C, Zipplies S, Ochs BG. Proximal humeral fractures in children and adolescents. $J$ Pediatr Orthop. 2009;29:238-42.

18. Beringer DC, Weiner DS, Noble JS. Severely displaced proximal humeral epiphyseal fractures: a follow-up study. J Pediatr Orthop. 1998;18:31-7.

19. Chen CY, Chao EK. Closed management and percutaneous fixation of unstable proximal humerus fractures. J Trauma 1998; 45:1039-45.

20. Soete PJ, Clayson PE. Transitory percutaneous pinning in fractures of the proximal humerus. J Shoulder Elbow Surg 1999; 8:569-73.

21. Herscovici D Jr, Saunders DT, Johnson MP, Sanders R, DiPasquale T. Percutaneous Fixation of Proximal Humeral Fractures. Clin Orthop Relat Res. 2000 Jun;(375):97-104. Review.

22. Fenichel I, Oran A, Burstein G, Perry M. Percutaneous pinning using threaded pins as a treatment option for unstable two- and three-part fractures of the proximal humerus: a retrospective study. Int Orthop 2006; 30:153-7.

23. Magovern B, Ramsey ML. Percutaneous fixation of proximal humerus fractures. Orthop Clin North Am 2008;39:405-16.
24. Keener JD, Parsons BO, Flatow EL, Rogers K, Williams GR. Outcomes after percutaneous reduction and fixation of proximal humerus fractures. $J$ Shoulder Elbow Surg 2007;16:330-8.

25. Nho SJ, Brophy RH, Baker JU, Cornell CN, MacGillivray JD. Management of proximal humerus fractures based on current literature. $J$ Bone Joint Surg Am 2007;89A:44-58.

26. Floris B, Weise K. Fractures of the proximal humerus in children. International Orthopedics 2003; 17:16-9.

27. Schwendenwein E .Displaced fractures of the proximal humerus in children require open/closed reduction and internal fixation. Eur J Pediatr Surg 2004; 14:51-5.

28. Odéhouri K, Gouli J C. Operative treatment of proximal humeral fractures in children: Indications and results. African Journal of Paediatric Surgery 2008; 5:20-4.

29. Rolauffs B, Heranz G. Proximal Humeral Fractures in Children and Adolescents. J Pediatr Orthop 2009; 29:238-42.

30. Binder H, Schurz M. Injuries of the proximal humerus: long-term results in seventy two patients. International Orthopaedics 2010; 9:12-7.

31. Muncibì F1, Paez DC, Matassi F, Carulli C, Nistri L. Long term results of percutaneous fixation of proxim al humerus fractures. Indian $J$ Orthop. 2012 Nov;46(6):664-7. 